\title{
Cryopreservation of great scallop (Pecten maximus) sperm: effect of extender, cryoprotectant and cooling rate on sperm survival
}

\author{
Marc SuQueT $^{\text {a }}$, Marie Eve Julie ARSENAUlt-Pernet, Dominique Ratiskol and Christian Mingant \\ Ifremer, UMR 5639, Physiologie fonctionnelle des organismes marins, Station expérimentale d'Argenton, Argenton, France
}

Received 13 May 2014; Accepted 25 June 2014

\begin{abstract}
To develop selection programs for the great scallop, artificial reproduction of the species needs to be improved by gamete cryobanking. Here, a set of four experiments was designed in order to define the basic elements of a cryopreservation protocol for scallop sperm, including extender composition (experiment 1), cryoprotectant selection (2), cooling rate (3), and assessment of the effects of sperm cryopreservation on sperm motility and fertilization capacity (4). Sperm was collected after serotonin injection (100 $\mu \mathrm{l}$ of a 10-mM solution) and frozen in 500- $\mu$ l straws. For the first three experiments, the percentage of motile fresh sperm $(80 \pm 4 \%$, mean \pm SEM $)$ was significantly higher than that observed for thawed sperm $(11 \pm 2 \%)$. During the first experiment, no significant difference of the percentage of motile thawed sperm was observed among the three saline extenders tested: seawater, calcium-free Hanks' balanced salt solution (Ca-free HBSS) and DCSB4 solution. However, a complementary experiment (2) showed that a significantly higher percentage of motile thawed sperm was recorded using DCSB4 than with Ca-free HBSS as an extender. During the third experiment, sperm motility was higher when using polyethylene glycol (10\% PEG) as a cryoprotectant, than when using dimethyl sulphoxide, DMSO (10 and 20\%), methanol (10\%) and ethylene glycol (10\% EG). A higher D-larval rate was obtained during the fourth experiment, using fresh sperm than thawed sperm, and using a 500:1 sperm-to-egg ratio compared with a 50:1 ratio. There is some evidence of inter-individual variations in sperm tolerance to cryopreservation. In conclusion, the highest survival of great scallop sperm after thawing was recorded using the following conditions: DCSB4 extender (1:3 vol/vol sperm to extender dilution), PEG cryoprotectant (10\%) and straws maintained at $5.5 \mathrm{~cm}$ above liquid nitrogen.
\end{abstract}

Keywords: Pecten maximus / sperm / cryopreservation / fertilization

\section{Introduction}

In Europe, the production of great scallop aquaculture decreased from 434 tonnes in 1996 to 74 tonnes in 2011, with the latter accounting for only $0.12 \%$ of the total production of great scallop fisheries (FAO 2014). However, statistics were conflicting because no quantities were reported for some countries (Andersen et al. 2011). Since the first initiative of great scallop culture in the 1970s (Gruffyd and Beaumont 1972), annual farming production has remained highly variable and the mean survival of $20 \mathrm{~mm}$ spat from the egg stage is less than $1 \%$ (Andersen et al. 2011). As a consequence, the stable year-round production of great scallop remains a challenge for hatcheries.

One of the difficulties with hatchery rearing of this species, is that of controlled scallop reproduction. The survival of three-day-old larvae ranged from 20 to $41 \%$ for scallops conditioned in the hatchery and induced to spawn by thermal shock

a Corresponding author: marc. suquet@ifremer.fr
(Magnesen and Christophersen 2008). At the industry production scale, a D-larval yield ranging from 10 to $60 \%$ was recorded (Robert and Gérard 1999). Although selection programs have been suggested for this species, artificial reproduction of the great scallop needs to be improved by: controlling gamete release, avoiding self-fertilization observed in this functional hermaphrodite which greatly decreases the subsequent growth rate of larvae (Beaumont and Budd 1983) and cryobanking gametes.

In marine species, sperm cryopreservation research has mainly been conducted on fish (Suquet et al. 2000). Since the review by Gwo (2000), however, studies on the cryopreservation of mollusc sperm have become more numerous, mainly concerning oyster species. Eastern oyster (Crassostrea virginica) sperm maintained a high motility when diluted in salt extenders: calcium-free Hanks' balanced solution (Ca-free HBSS) or DCSB4 (Paniagua-Chavez et al. 1998). Concerning the choice of cryoprotectant, the best survival of thawed sperm was observed using ethylene glycol in mussel (Mytilus galloprovincialis, Di Matteo et al. 2009), methanol, ethylene 
glycol and DMSO in Pacific oyster (Crassostrea gigas, Dong et al. 2007) and propylene glycol in Eastern oyster (PaniaguaChavez and Tiersch 2001). In Pacific oyster, a simple protocol of sperm cryopreservation was defined, including extender composition, cryoprotectant selection, cooling and thawing rates (Dong et al. 2009). A commercial scale protocol has also been published, and is suitable for routine conservation of $\mathrm{Pa}-$ cific oyster sperm in selection programs (Adams et al. 2009).

In scallop, the biological characteristics of sperm remain poorly studied. Sperm is of the primitive type with an acrosome (Dorange and Le Pennec 1989). A sperm "maturation process" has been described along the scallop genital tract and the shedding of fully mature sperm was observed after intragonadal serotonin injection or thermal shock (Suquet et al. 2013). Sperm activation in seawater triggers a high respiration rate and sperm movement which lasts for a few hours (Faure et al. 1994a).

Short term storage of scallop sperm was successfully reported at $4{ }^{\circ} \mathrm{C}$, but sperm movement has been observed to decrease from 60 to $0 \%$ after 6 days (Micarrelli 1994). At present, no study reports the cryopreservation of scallop sperm. In closely related pectinid species, Argopecten purpuratus, the percentage of motile sperm was halved after sperm freezing using 10\% DMSO as a cryoprotectant (Espinoza et al. 2010). In the same species, a cooling rate of $9{ }^{\circ} \mathrm{C} \mathrm{min}-1$ resulted in 51\% motile thawed sperm (Dupre 2004). The aims of the present paper are to define the basic elements of a cryopreservation protocol of scallop sperm, including extender composition, cryoprotectant, and cooling rate, and to assess the effects of sperm cryopreservation on sperm motility and fertilization capacity.

\section{Materials and methods}

\subsection{Broodstock}

Adult scallops $(n=100 ; 183 \pm 28 \mathrm{~g}$, mean weight \pm SEM; $11.0 \pm 0.7 \mathrm{~cm}$, mean length $\pm \mathrm{SEM}$ ) were collected in the bay of Brest (Finistère, France) at the beginning of the natural spawning season (April 2013) which ranged from April to October (Paulet et al. 1988). The scallops were then transferred to the Argenton experimental hatchery (Ifremer) where they were conditioned in $600-\mathrm{L}$ race ways, containing seawater $(\mathrm{SW})$ : $17{ }^{\circ} \mathrm{C}$ temperature and 34.0 salinity. Great scallops were fed daily on a mixture of Isochrysis galbana and Chaetoceros calcitrans for one month.

\subsection{Sperm collection}

The scallops were treated with $100 \mu \mathrm{l}$ of a $10-\mathrm{mM}$ serotonin solution diluted in distilled water and injected into the male gonads. They were then transferred into 2-L beakers filled with $0.5 \mathrm{~L}$ seawater $\left(17^{\circ} \mathrm{C}, 1-\mu \mathrm{m}\right.$ filtration $)$ where sperm shedding was observed 10 to 30 min after serotonin injection. Sperm samples were pipetted directly from the sperm plume (close to the gonopore) to collect highly concentrated samples, and stored at $4{ }^{\circ} \mathrm{C}$ until use.

\subsection{Sperm cryopreservation}

The general procedure of cryopreservation was as follows: sperm samples were diluted in one step in different extenders. For each straw, a $125 \mu \mathrm{l}$ sperm: $375 \mu \mathrm{l}$ (extender + cryoprotectant-CPA: $10 \%$ polyethylene glycol-PEG, unless otherwise stated) ratio was used. The extenders and CPA were maintained at room temperature $\left(19^{\circ} \mathrm{C}\right)$. Sperm samples were frozen in $500-\mu 1$ straws (IMV, France, straw triplicate). No equilibration time was allowed. Straws were transferred to a tray floating at $5.5 \mathrm{~cm}$ above the surface of liquid nitrogen (LN), and maintained in a polystyrene box. After $10 \mathrm{~min}$, the straws were plunged into $\mathrm{LN}$ and maintained in $\mathrm{LN}$ during $30 \mathrm{~min}$. Then, the straws were thawed in a water bath $\left(25^{\circ} \mathrm{C}\right)$ for $15 \mathrm{~s}$.

\subsection{Sperm quality assessment}

Sperm motility was estimated as previously described in Suquet et al. (2013): briefly, the sperm was diluted (1:625 dilution rate) in $\mathrm{SW}$ (33.7 salinity, $20^{\circ} \mathrm{C}, 7.72 \mathrm{pH}, 5 \mathrm{~g} \mathrm{~L}^{-1}$ bovine serum albumin, BSA avoiding sperm aggregation when activated). Sperm samples of $7 \mu \mathrm{l}$ were transferred to a Thomas cell (Brand, Main, Germany) and sperm motility was observed under a phase contrast microscope (Olympus BX 51, X 20 magnification): the percentage of motility was visually assessed on films (Sony camera, 60 frames s ${ }^{-1}, 10 \mathrm{~s}$ film duration, $3 \times 30$ spermatozoa). Only scallops with a percentage of motile fresh sperm higher than $60 \%$ were selected for the sperm cryopreservation assays.

Sperm concentration was determined by Coulter Counter after 1:500 dilution in SW (in duplicate). The total number of spermatozoa was calculated (sperm concentration $\times$ seawater volume in the beaker). Sperm fertilization capacity was assessed in the following way: eggs were obtained by thermal shock (from 18 to $23{ }^{\circ} \mathrm{C}$ ), according to Gruffydd and Beaumont (1970). As soon as the first eggs were shed, the scallops were carefully washed with SW to avoid selffertilization and individually transferred in 2-L beakers, filled with 0.5 -L SW at $23{ }^{\circ} \mathrm{C}$. Eggs collected from three females were pooled, transferred to a 2 -L cylinder filled with SW and counted $(3 \times 50 \mu \mathrm{l})$. Eggs were fertilized following the standardized protocol previously defined by Song et al. (2009) for Pacific oyster eggs and adapted to scallops: triplicate lots of 25000 eggs each were fertilized in $50 \mathrm{ml} \mathrm{SW}$, using different sperm-to-egg ratios. After $30 \mathrm{~min}$ of contact between sperm and eggs, the beakers were filled with 2-L SW. The D-larval yield was estimated for each beaker, $48 \mathrm{~h}$ post fertilization: larvae were filtered, transferred in $10 \mathrm{ml}$ seawater and counted $(3 \times 50 \mu \mathrm{l})$. Non-viable larvae (translucent or non D-shaped) were not included. In order to estimate self-fertilization, triplicate samples of the egg pool were incubated without sperm addition. The D-larval yield was calculated: [(number of D larvae - number of self-fertilized D larvae)/25000 eggs] $\times 100$.

\subsection{Experimental design}

A set of four cryopreservation experiments was carried out, using five males for each. For the first three experiments, the 
percentages of motile fresh and thawed sperm were assessed and for the 4th experiment the D-larval rate was estimated.

The first experiment examined the effect on sperm motility of three extenders: seawater $\left(7.80 \mathrm{pH}, 1020 \mathrm{mOsmolL}^{-1}\right.$ osmotic pressure; Ca-free HBSS (7.23 pH, $797 \mathrm{mOsmol} \mathrm{L}^{-1}$; composition: Paniagua-Chavez et al. 1998) and DCSB4 solution (7.76 pH, $695 \mathrm{mOsmol} \mathrm{L}^{-1}$; composition: PaniaguaChavez et al. 1998). Dimethyl sulphoxide (10\% DMSO) was used as a CPA.

In the second experiment, the effects of four CPA were evaluated: DMSO (10 and 20\%), polyethylene glycol (10\% PEG), methanol (10\% MET) and ethylene glycol (10\% EG); DCSB4 and Ca-free HBSS were used as extenders.

In the third experiment, the effects of three cooling rates were assessed, maintaining straws on a floating tray at different heights above the $\mathrm{LN}$ surface $\left(3.0 \mathrm{~cm},-163{ }^{\circ} \mathrm{C}\right.$ final temperature, $5.5 \mathrm{~cm},-88{ }^{\circ} \mathrm{C}$ and $8.0 \mathrm{~cm},-17{ }^{\circ} \mathrm{C}$, Dostmann Electronic Thermometer, Wertheim, Germany), using DCSB4 as an extender and DMSO (20\%) or PEG (10\%) as the CPA.

In the fourth experiment, the fertilization capacity of thawed sperm was compared with that of fresh sperm, following the protocol described above (DCSB4 extender, 10\% PEG cryoprotectant, tray at $5.5 \mathrm{~cm}$ above LN). Three sperm pools (collected from two males each) were used. Two different sperm-to-egg ratios were used: 50:1 and 500:1 (Faure et al. 1994b). Triplicate controls were added (in which no sperm was added to eggs) to estimate the self-fertilization rate.

\subsection{Statistical analysis}

Results are presented as mean \pm SEM. The percentage of motile sperm and D-larval yields were arcsin square root transformed and their means compared using Student $t$-tests or two- or three-way ANOVA. For ANOVA, and when differences were significant, a Fisher a posteriori test was used for means comparisons.

\section{Results}

The total number of spermatozoa individually shed after serotonin injection, ranged from 4.7 to $60.0 \times 10^{9}$ (mean: $18.8 \pm 7.4 \times 10^{9}, n=8$ great scallops). For the first three experiments, the mean percentage of motile fresh sperm $(80 \pm 4 \%)$ was significantly higher than the percentage of motile thawed sperm $(11 \pm 2 \%, p=0.001)$. During the first experiment, the percentage of motile thawed sperm was significantly different among males $(p=0.001)$. However, no significant difference in the percentage of motile thawed sperm was observed among the three extenders $(6 \pm 2 \% \mathrm{SW}, 9 \pm 4 \% \mathrm{Ca}$-free HBSS and $12 \pm 5 \%$ DCSB4). On the contrary, in the second experiment a significantly higher percentage of motile thawed sperm was recorded using DCSB4 compared with Ca-free HBSS ( $p=$ 0.007 , Fig. 1A). Furthermore, higher percentages of motile spermatozoa were observed using $10 \%$ PEG or $20 \%$ DMSO, than with other CPA ( $p=0.031$, Fig. 1B). A significant variation in thawed sperm motility was observed between males $(p=0.018)$ and there was a significant interaction between males and CPA $(p=0.001)$.
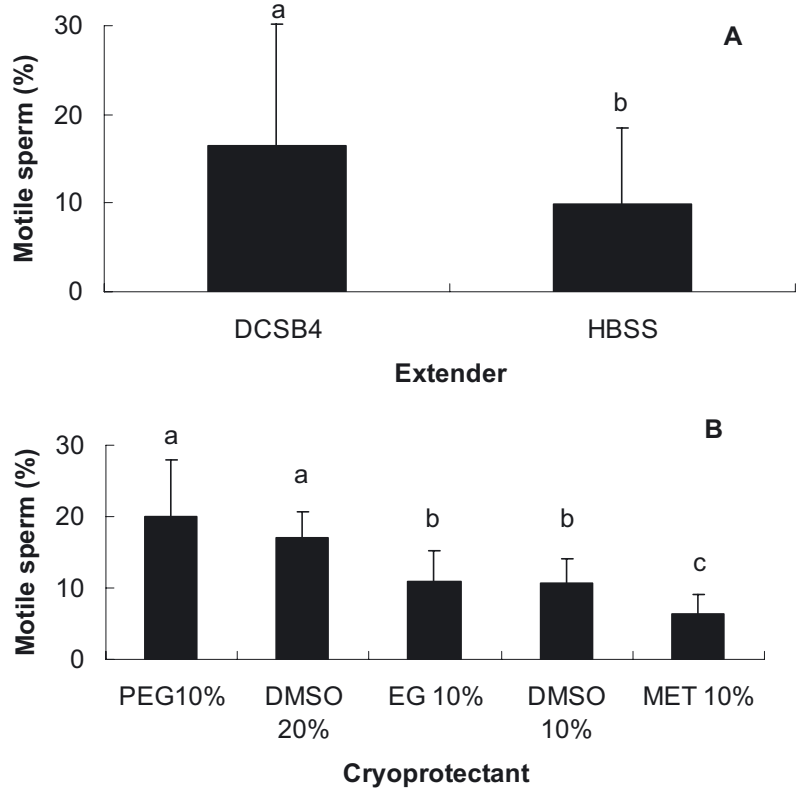

Fig. 1. Effect of extender (A) and cryoprotectant (B) on the percentage of motile post-thaw spermatozoa $(n=5$ great scallops, different letters indicate significantly different results).
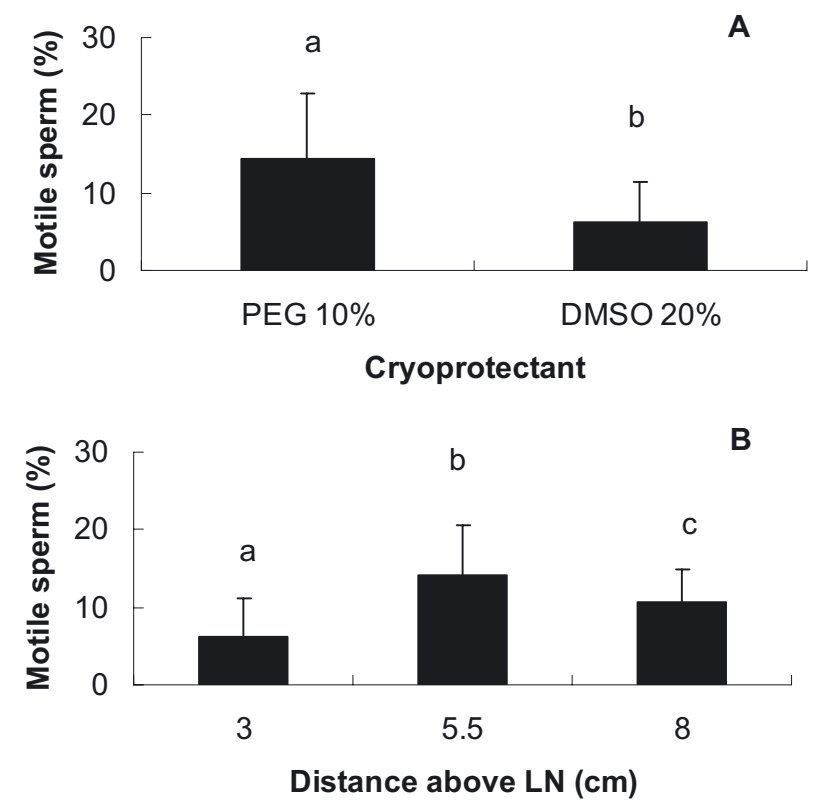

Fig. 2. Effect of cryoprotectant (A) and distance above liquid nitrogen surface (B) on the percentage of motile post-thaw spermatozoa $(n=5$ great scallops, different letters indicate significantly different results).

During the third experiment, higher sperm motility was found when using $10 \%$ PEG as a CPA than when using $20 \%$ DMSO ( $p=0.001$, Fig. 2A). Maintaining straws at $5.5 \mathrm{~cm}$ above $\mathrm{LN}$ led to greater sperm motility than maintaining them at 3.0 or $8.0 \mathrm{~cm}(p=0.030$, Fig. $2 \mathrm{~B})$.

During the fourth experiment, the mean D-larval rate for self-fertilized samples was $4 \pm 1 \%$. Significantly higher 

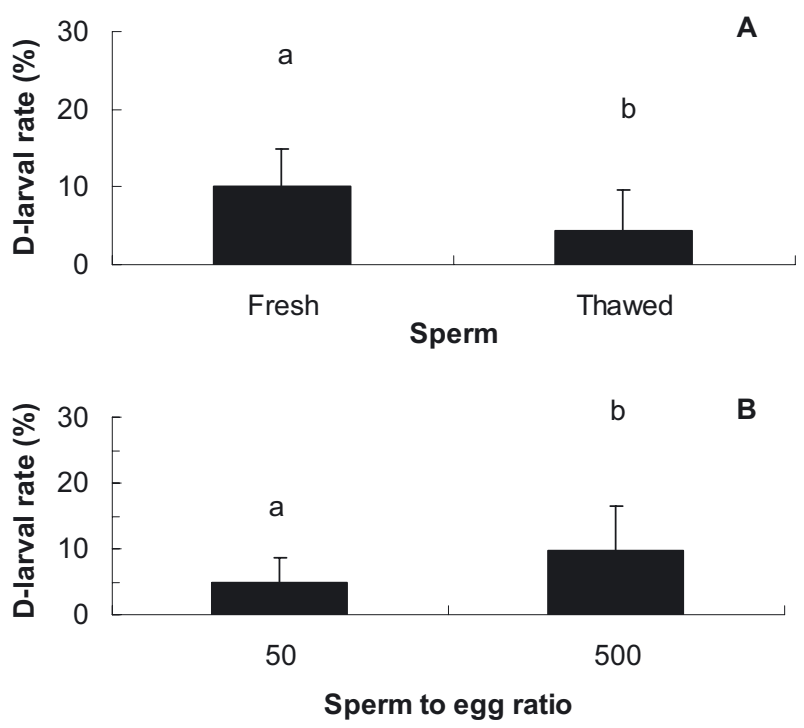

Fig. 3. Effect of cryopreservation on the fertilization capacity of thawed sperm (A). Effect of sperm-to-egg ratio on the fertilization capacity of sperm (B) $(n=5$ great scallops, different letters indicate significantly different results).

D-larval rates were found using fresh sperm than thawed sperm ( $p=0.001$, Fig. 3A) and using 500 sperm for one egg compared with 50 ( $p=0.001$, Fig. 3B). Furthermore, sperm pools 2 and 3 gave significantly higher D-larval rates than pool 1 ( $p=0.001)$. Significant interactions were also observed between sperm status (fresh vs. thawed) and sperm pool $(p=0.001)$ and between sperm-to-egg ratio and sperm pool $(p=0.002)$.

\section{Discussion}

The present study demonstrates that great scallop sperm can be successfully frozen and thawed. The fertilization capacity of thawed sperm remains limited $(9 \pm 4 \%$ D-larval rate, for a sperm-to-egg ratio of 500:1), but was close to the mean D-larval rate obtained in the present study using fresh sperm (12 $\pm 3 \%$, same sperm-to-egg ratio). Also working with fresh sperm, Robert and Gérard (1999) obtained a limited D-larval rate of $29 \%$. These results underline the low control we have of great scallop artificial reproduction.

Self-fertilization is often reported in great scallop: the species is a functional hermaphrodite that emits both sperm and oocytes via a common gonoduct (Widowati et al. 1995). Great scallop larvae issued from self-fertilization grow slower than other great scallop larvae, suggesting this low growth could be due to reduced heterozygosity (Beaumont and Budd 1983). To decrease self-fertilization rate, the first batch of eggs, which is often contaminated with sperm, must be discarded (Andersen et al. 2011). Although this procedure was carried out in the present study, 4 to $5 \%$ of the eggs were found to be self-fertilized in the control samples. In a closely-related scallop species, Argopecten purpuratus, Martinez et al. (2007) suggested a technique of avoiding selffertilization by using meiosis reinitiation of striped oocytes and artificial fertilization.
Pure sperm is not suitable for freezing because of its high concentration of spermatozoa, mean that it cannot be mixed homogeneously with a cryoprotectant agent (CPA). In great scallop, it is not necessary to inhibit sperm movement before freezing because sperm movement has a long duration, lasting 8 to $10 \mathrm{~h}$ depending on males. This long movement duration is sustained by a gradual decrease of sperm intracellular ATP level during the movement phase: $19 \%$ of the initial ATP content is exhausted $1 \mathrm{~h}$ post-activation and $40 \%$ after $3 \mathrm{~h}$ (Suquet et al. 2013). The effect of extender composition has only been rarely studied in bivalves. At $4{ }^{\circ} \mathrm{C}$, the storage capacity of American oyster sperm did not differ when using seawater, HBSS or DCSB4 solution (Paniagua-Chavez et al. 1998). Using Ca-free HBSS, these authors did not observe sperm agglutination, suggesting acrosome damage was prevented. In the present study, the use of different breeders between experiments may explain the higher percentage of motile thawed spermatozoa observed using DCSB4 compared to Ca-free HBSS in the 2nd experiment, while this difference was not recorded during the 1 st experiment.

The selection of the optimal CPA is often the main focus of studies dealing with sperm cryopreservation. PEG, the only non-permeating (unable to pass through the sperm membrane) CPA used in the present study, was the most efficient substance among those studied in the present work. PEG was also more effective than permeating CPA (MET, EG, DMSO, propylene glycol and glycerol) in maintaining the movement of Pacific oyster sperm post-thaw, while a combination of PEG with a permeating CPA (DMSO or MET) was effective in promoting sperm motility and fertilization capacity (Dong et al. 2005a). DMSO (8\%) has been used for commercial-scale cryopreservation of Pacific oyster sperm (Dong et al. 2005b). The success of DMSO can be explained by its fast penetration into spermatozoa and by its interaction with the phospholipids of the sperm membrane (Ogier de Baulny et al. 1996). However, high concentrations of DMSO can be toxic, which could explain the lower percentage of motile thawed spermatozoa observed in the present study, using 20\% DMSO compared with $10 \%$ PEG. Adding 7\% EG led to the highest percentage of motile thawed sperm of mussel and the highest fertilization success (Di Matteo et al. 2009). In great scallop, the lowest percentage of motile sperm was noted using MET. Compared to DMSO and propylene glycol, MET was considered as more toxic for oyster (Crassostrea rhizophorae) sperm (Nascimento et al. 2005). The effect of different concentrations of PEG and of a combination of permeating and non permeating cryoprotectants will be further studied in great scallop.

Straws can be subjected to different cooling rates by simply modifying the height of the floating tray above the surface of liquid nitrogen, LN surface. The highest motility of thawed great scallop sperm was obtained when straws were placed at $5.5 \mathrm{~cm}$ above the $\mathrm{LN}$ (corresponding to $-88^{\circ} \mathrm{C}$ measured after 5 min). During this phase, sperm survival depends on intracellular ice formation and salt concentration, both parameters being modified by the movement of water out of the cell as the temperature decreased (Cloud and Patton 2009). Post thaw motility of Japanese pearl oyster (Pinctada fucata martensii) sperm was lower than $5 \%$ when straws were maintained at $7.5 \mathrm{~cm}$ above $\mathrm{LN}$ and increased abruptly to $35-40 \%$ at $10 \mathrm{~cm}$ 
(Kawamoto et al. 2007). Compared to great scallop sperm, a close height above LN of $5.2 \mathrm{~cm}$ was used for greenlip abalone (Haliotis laevigata, Liu et al. 2014).

In the present study, we obtained a higher D-larval rate using 500 sperm per egg compared with 50. This suggests that the sperm-to-egg ratio of $1: 1$ to $5: 1$ previously reported by Gruffydd and Beaumont (1972) could be an underestimate for great scallop. A 2.5 fold decrease of the fertilization capacity of great scallop sperm was observed in the thawed batch compared with fresh sperm, probably reflecting the lower number of motile thawed sperm relative to the control. A reduction of the fertilization capacity by 30 to 100 fold relative to control was also reported in Pacific oyster (Adams et al. 2004). This reduced capacity can be compensated by increasing the spermto-egg ratio.

Additionally, in three of the four experiments reported in this paper, inter-individual variations of post-thawing sperm survival were noted. These results agree with the interindividual variations of sperm traits previously reported in great scallop (Devauchelle et al. 1994). According to Dong et al. (2005a), this suggests a variation in the tolerance to the cryopreservation process, i.e. sperm individual fertilization capacity after thawing. Studies dealing with mollusc sperm cryopreservation most often focus on technical improvements, including extender composition, cryoprotectant selection and cooling and thawing rates. However, they often lack a complete description of post-thawing morphological and metabolic changes to sperm. As a consequence, this preliminary study will be followed up by further research comparing pre- and post-thawing sperm quality.

Acknowledgements. The authors thank Stephane Pouvreau (Ifremer) for scallop fishing and Catherine Labbé (INRA), Fabrice Pernet (Ifremer) and Ismaël Bernard (Eureka Modelisation) for fruitful discussions on the protocol and statistical treatments. We thank Helen McCombie for her help in editing the English. This work was supported by the national project CRB anim funded by Investissements d'Avenir (ANR-11-INBS-0003).

\section{References}

Adams S.L., Smith J.F., Roberts R.D., Janke A.R., Kaspar H.F., Tervit H.R., Pugh P.A., Webb S.C., King N.G., 2004, Cryopreservation of sperm of the Pacific oyster (Crassostrea gigas): development of a practical method for commercial spat production. Aquaculture 242, 271-282.

Adams S.L., Smith J.F., Roberts R.D., Janke A.R., Kaspar H.F., Tervit H.R., Pugh P.A., Webb S.C., King N.G., 2009, A simple method for freezing Pacific oyster (Crassostrea gigas) sperm in quantities suitable for commercial hatcheries. In: Cabrita E., Robles V., Herraez P. (Eds.), Methods in reproductive aquaculture, Boca Raton, USA, CRC Press, pp. 493-495.

Andersen S., Christophersen G., Magnesen T., 2011, Spat production of the great scallop (Pecten maximus): a roller coaster. Can. J. Zool. 89, 579-598.

Beaumont A.R., Budd M.D., 1983, Effects of self-fertilization and other factors on the early development of the scallop Pecten maximus. Mar. Biol. 76, 285-289.

Cloud J., Patton S., 2009, Basic principles of fish spermatozoa cryopreservation. In: Cabrita E., Robles V., Herraez P. (Eds.), Methods in reproductive aquaculture, Boca Raton, USA, CRC Press, pp. 237-250.
Devauchelle N., Faure C., Girard J.P., 1994, The quality of sperm of two bivalves: the oyster, Crassostrea gigas and the scallop, Pecten maximus. In: Muir J., Sevila F. (Eds.) Measures for success, Eur. Aquac. Soc., Spec. Publ. 21, 214-216.

Di Matteo O., Langellotti A.L., Masullo P., Sansone G., 2009, Cryopreservation of the Mediterranean mussel (Mytilus galloprovincialis) spermatozoa. Cryobiology 58, 145-150.

Dong Q., Huang C., Eudeline B., Tiersch T.R., 2005a, Systematic factor optimization for cryopreservation of shipped sperm samples of diploid Pacific oysters, Crassostrea gigas. Cryobiology 51, 176-195.

Dong Q., Eudeline B., Huang C., Allen S.K.J., Tiersch T.R., 2005b, Commercial-scale sperm cryopreservation of diploid and tetraploid Pacific oyster, Crassostrea gigas. Cryobiology 50, $1-16$.

Dong Q., Huang C., Eudeline B., Tiersch T.R., 2007, Cryoprotectant optimization for sperm of diploid Pacific oysters by use of commercial dairy sperm freezing facilities. Aquaculture 271, 537-545.

Dong Q., Huang C., Eudeline B., Tiersch T.R., 2009, Cryopreservation of Pacific oyster sperm. In: Cabrita E., Robles V., Herraez P. (Eds.), Methods in reproductive aquaculture, Boca Raton, USA, CRC Press, pp. 487-491.

Dorange G., Le Pennec M., 1989, Ultrastructural characteristics of spermatogenesis in Pecten maximus (Mollusca, bivalvia). Invertebr. Reprod. Dev. 15, 109-117.

Dupré E., 2004, Freezing of spermatozoa of the scallop Argopecten purpuratus using a mechanical freezing system. Invest. Mar. Valparaiso 32, 3-9.

Espinoza C., Valdivia M., Dupré E., 2010, Morphological alterations in cryopreserved spermatozoa of scallop Argopecten purpuratus. Lat. Am. J. Aquat. Res. 38, 121-128.

FAO, 2014, Fisheries and aquaculture information and statistics service. Food and Agricultural Organization of the United Nations, FAO, Rome.

Faure C., Devauchelle N., Girard J.P., Cosson J., 1994a, The quality of Pecten maximus sperm. Can. Tech. Rep. Fish. Aquat. Sci. 1994, 28-37.

Faure C., Devauchelle N., Girard J.P., 1994b, Ionic factors affecting motility, respiration and fertilization rate of the sperm of the bivalve Pecten maximus (L.). J. Comp. Physiol. B 164, 444-450.

Gruffydd L.D., Beaumont A.R., 1970, Determination of the optimum concentration of eggs and spermatozoa for the production of normal larvae in Pecten maximus (Mollusca, Lamellibranchia). Helgolander wiss. Meeresunters. 20, 486-497.

Gruffydd L.D., Beaumont A.R., 1972, A method for rearing Pecten maximus larvae in laboratory. Mar. Biol. 15, 350-355.

Gwo J.C., 2000, Cryopreservation of aquatic invertebrate semen: a review. Aquac. Res. 31, 259-271.

Kawamoto T., Narita T., Isowa K., Aoki H., Hayashi M., Komaru A., Ohta H., 2007, Effects of cryopreservation methods on post-thaw motility of spermatozoa from the Japanese pearl oyster, Pinctada fucata martenssi. Cryobiology 54, 19-26.

Liu Y., Xu T., Robinson N., Qin J., Li X., 2014, Cryopreservation of sperm in farmed Australian greenlip abalone Haliotis laevigata. Cryobiology 68, 185-193.

Magnesen T., Christophersen G., 2008, Reproductive cycle and conditioning of translocated scallops (Pecten maximus) from five broodstock populations in Norway. Aquaculture 285, 109-116.

Martinez G., Mettifogo L., Perez M.A., Callejas C., 2007. A method to eliminate self-fertilization in a simultaneous hermaphrodite scallop. 1. Effects on growth and survival of larvae and juveniles. Aquaculture 273, 459-469. 
Micarelli P., 1994, Preliminary data on cryoconservation of the male gametes of the scallop Pecten maximus, for experimental purposes and development of aquaculture. Riv. Ital. Acquac. 29, $31-37$.

Nascimento I.A., Leite M.B.N.L., Sampaio de Araujo M.M., Sansone G., Periera S., Espirito Santo M, 2005, Selection of cryoprotectants based on their toxic effects on oyster gametes and embryos. Cryobiology 51, 113-117.

Ogier de Baulny B., Le Vern Y., Kerboeuf D., Heydorff M., Maisse G., 1996, Flow cytometric analysis of plasma membrane damages of rainbow trout and turbot frozen sperm. In: Proceedings of the Commission C2, Refrigeration and Production, Int. Symp. Froid et Aquaculture, pp. 65-72 (available : http://www.gbv.de/ dms/tib-ub-hannover/230047653.pdf)

Paniagua-Chavez C., Tiersch T.R., 2001, Laboratory studies of cryopreservation of sperm and trochophore larvae of the Eastern oyster. Cryobiology 43, 211-223.

Paniagua-Chavez C., Buchanan J.T., Tiersch T.R., 1998, Effect of extender solutions and dilution on motility and fertilizing ability of Eastern oyster sperm. J. Shellfish Res. 17, 231-237.
Paulet Y.M., Lucas A., Gerard A., 1988, Reproduction and larval development in two Pecten maximus (L.) populations from Brittany. J. Exp. Mar. Biol. Ecol. 119, 145-156.

Robert R., Gérard A., 1999, Bivalve hatchery technology: The current situation for the Pacific oyster Crassostrea gigas and the scallop Pecten maximus in France. Aquat. Living Resour. 12, 121-130.

Song Y.P., Suquet M., Quéau I., Lebrun L., 2009, Setting of a procedure for experimental fertilization of Pacific oyster (Crassostrea gigas) oocytes. Aquaculture 287, 311-314.

Suquet M., Dreanno C., Fauvel C., Cosson J., Billard R., 2000, Cryopreservation of sperm in marine fish. Aquac. Res. 31, 231243.

Suquet M., Quéré C., Mingant C., Lebrun L., Ratiskol D., Miner P., Cosson J., 2013, Effect of sampling location, release technique and time after activation on the movement characteristics of scallop (Pecten maximus) sperm. Aquat. Living Resour. 26, 215-220.

Widowati I., Dorange G., Le Pennec M., Cochard J.C., 1995, Genital tract and oocyte pathway during the spawning in Pecten maximus (Molluscs, Bivalvia). Invertebr. Reprod. Dev. 28, 153-160. 